\title{
The Transition State for Carboxylic Acid Deprotonation on $\mathrm{Cu}(100)$
}

\author{
Boonchuan Immaraporn, ${ }^{\dagger}$ Pingping Ye, ${ }^{\dagger}$ and Andrew J. Gellman $*,+$ \\ Department of Chemistry and Department of Chemical Engineering, Carnegie Mellon University, \\ Pittsburgh, Pennsylvania 15213
}

Received: July 14, 2003; In Final Form: December 14, 2003

\begin{abstract}
The kinetics of acid deprotonation on the $\mathrm{Cu}(100)$ surface have been studied using four different fluorinated carboxylic acids $\left(\mathrm{CF}_{2} \mathrm{HCO}_{2} \mathrm{H}, \mathrm{CF}_{3} \mathrm{CO}_{2} \mathrm{H}, \mathrm{CF}_{2} \mathrm{HCF}_{2} \mathrm{CO}_{2} \mathrm{H}\right.$, and $\left.\mathrm{CF}_{3} \mathrm{CF}_{2} \mathrm{CO}_{2} \mathrm{H}\right)$. All four acids adsorb molecularly on $\mathrm{Cu}(100)$ at $90 \mathrm{~K}$ but deprotonate during heating to form carboxylates on the surface at temperatures below $300 \mathrm{~K}$. Temperature-programmed reaction spectroscopy and X-ray photoemission spectroscopy were used to verify that the acids deprotonate on the $\mathrm{Cu}(100)$ surface. Work function measurements were used to study the deprotonation kinetics during heating and to estimate the activation energy barriers $\left(\Delta E_{\mathrm{O}-\mathrm{H}}^{\ddagger}\right)$ to deprotonation. The nature of the transition state to acid deprotonation on $\mathrm{Cu}(100)$ was probed by analysis of linear free energy relationships (LFER) or correlations of $\Delta E_{\mathrm{O}-\mathrm{H}}^{\ddagger}$ with the acid substituent constants, $\sigma_{\mathrm{F}}$. The field reaction constant, $\rho_{\mathrm{F}}$, or the slope of the LFER was found to be $\rho_{\mathrm{F}}=-52 \pm 13 \mathrm{~kJ} / \mathrm{mol}$ in the limit of zero coverage and $\rho_{\mathrm{F}}=-19 \pm 2 \mathrm{~kJ} / \mathrm{mol}$ at a coverage of $1 / 2 \mathrm{ML}$. These values of $\rho_{\mathrm{F}}$ can be compared to the value of $\rho_{\mathrm{F}}=-104 \mathrm{~kJ} / \mathrm{mol}$ for acid deprotonation in the gas phase. This comparison suggests that the transition state for acid deprotonation on $\mathrm{Cu}(100)$ must be anionic with respect to the reactant $\left(\mathrm{RCO}_{2} \mathrm{H}_{(\mathrm{ad})} \leftrightarrow\right.$ $\left[\mathrm{RCO}_{2}{ }^{\delta-} \cdot \cdots \mathrm{H}^{\delta+}\right]^{\sharp} \rightarrow$ ).
\end{abstract}

\section{Introduction}

Since heterogeneous catalysis is fundamentally a kinetic phenomenon, characterizing the transition states to elementary steps in catalytic surface reaction mechanisms is critical to understanding the influence of catalysts on activation barriers and catalytic reaction kinetics. Unfortunately, few experimental approaches to examining the nature of transition states on surfaces are available. One approach is to use substituent effects, a method that has often been employed in gas-phase and solution-phase reactions. The application of substituent effects in surface chemistry, however, is still limited. ${ }^{1}$ The elimination of $\beta$-hydride in alkoxides on the $\mathrm{Cu}(111)$ surface is an example of a surface reaction in which substituent effects have been used to show that the transition state is cationic with respect to the reactant, $\left[\mathrm{RC}^{\delta+} \cdot . \cdot \mathrm{H}^{\delta-}\right]^{\ddagger} \cdot{ }^{2,3}$ Another reaction for which substituent effects have been used as probes of the transition state is the dehalogenation of alkyl iodides on $\operatorname{Ag}(111)$ and $\operatorname{Pd}(111)$ surfaces. ${ }^{4-6}$ Deiodination kinetics were measured using a series of alkyl iodides with a wide range of substituent groups. In that case the transition state was found to be homolytic or reactant-

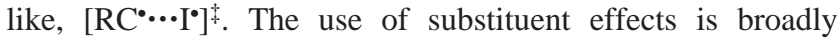
applicable and can be a valuable tool for expanding the scope of our understanding of catalytic processes. ${ }^{7-9}$

The work presented in this paper expands on a previous study of the nature of the transition state for carboxylic acid deprotonation on Ag single-crystal surfaces. ${ }^{10}$ That work examined the surface chemistry of $\mathrm{CH}_{3} \mathrm{CO}_{2} \mathrm{H}$ and $\mathrm{CF}_{3} \mathrm{CO}_{2} \mathrm{H}$ on $\mathrm{Ag}(111)$ and $\mathrm{Ag}(110)$ surfaces. In summary, $\mathrm{CH}_{3} \mathrm{CO}_{2} \mathrm{H}$ adsorbs reversibly on the $\mathrm{Ag}$ surfaces and desorbs during heating while $\mathrm{CF}_{3}$ $\mathrm{CO}_{2} \mathrm{H}$ deprotonates on the surface to form $\mathrm{CF}_{3} \mathrm{CO}_{2}-\mathrm{Ag}$. Unfortunately, measurement of the deprotonation kinetics was

* Author to whom correspondence should be addressed. E-mail: gellman@ cmu.edu.

$\dagger$ Department of Chemistry.

$\doteqdot$ Department of Chemical Engineering. complicated by the fact that a fraction of the adsorbed $\mathrm{CF}_{3}-$ $\mathrm{CO}_{2} \mathrm{H}$ desorbed during heating. Although the barrier to deprotonation, $\Delta E_{\mathrm{O}-\mathrm{H}}^{\ddagger}$, of $\mathrm{CF}_{3} \mathrm{CO}_{2} \mathrm{H}$ was shown to be lower than that of $\mathrm{CH}_{3} \mathrm{CO}_{2} \mathrm{H}$, the results did not allow us to distinguish between heterolytic and homolytic descriptions of the transition state for acid deprotonation on the $\mathrm{Ag}(111)$ surface. A more quantitative study requires surfaces on which the deprotonation reaction is substantially faster than desorption. Carboxylic acids are known to deprotonate on single-crystal surfaces of metals such as $\mathrm{Cu}^{11-17}$ or Pt. ${ }^{18,19}$ Since there have been a number of studies of both carboxylic acids and carboxylates on $\mathrm{Cu}$ surfaces, they are good candidates for a thorough study of acid deprotonation kinetics.

The surface chemistry of formic acid and acetic acid has been studied on all three low Miller index surfaces of copper. On the $\mathrm{Cu}(110)$ surface, Bowker and Madix found that acetic acid adsorbs molecularly on the clean surface at $140 \mathrm{~K} .{ }^{16}$ During heating, acid deprotonation occurred at temperatures between 140 and $375 \mathrm{~K}$ to produce adsorbed formate and acetate. Molecular desorption of acetic acid was also observed at 240 $\mathrm{K}$. The hydrogen atoms generated on the surface as a result of deprotonation recombine to desorb as $\mathrm{H}_{2}$ at $310 \mathrm{~K}$. The formate and acetate were stable during heating until the temperature reached $\sim 600 \mathrm{~K}$, at which point they decomposed to produced $\mathrm{H}_{2}, \mathrm{CO}_{2}$, and other species that desorbed into the gas phase. The barrier to the deprotonation of acetic acid on the $\mathrm{Cu}(110)$ surface was measured by Lee et al. and found to vary from $\Delta E_{\mathrm{O}-\mathrm{H}}^{\ddagger}=37.6 \mathrm{~kJ} / \mathrm{mol}$ at low coverages to $\Delta E_{\mathrm{O}-\mathrm{H}}^{\ddagger}=106 \mathrm{~kJ} /$ mol at high coverages. ${ }^{11}$ The focus of the work described in this paper is the nature of the transition state to deprotonation of acids on the $\mathrm{Cu}(100)$ surface which will be probed through measurements of $\Delta E_{\mathrm{O}-\mathrm{H}}^{\ddagger}$. Clearly, the existing studies indicate that attention must be paid to the coverage dependence of these measurements.

We have attempted to probe the nature of the transition state for acid deprotonation on the $\mathrm{Cu}(100)$ surface using substituent 
effects. Measurements have been made of the deprotonation reaction kinetics using a series of fluorinated carboxylic acids $\left(\mathrm{CF}_{2} \mathrm{HCO}_{2} \mathrm{H}, \mathrm{CF}_{3} \mathrm{CO}_{2} \mathrm{H}, \mathrm{CF}_{2} \mathrm{HCF}_{2} \mathrm{CO}_{2} \mathrm{H}\right.$, and $\left.\mathrm{CF}_{3} \mathrm{CF}_{2} \mathrm{CO}_{2} \mathrm{H}\right)$ adsorbed on the $\mathrm{Cu}(100)$ surface. Temperature-programmed reaction spectroscopy (TPRS) and X-ray photoemission spectroscopy (XPS) were used to show that all four carboxylic acids deprotonate to form carboxylates on the $\mathrm{Cu}(100)$ surface at temperatures in the range $150-300 \mathrm{~K}$. The carboxylates decompose during further heating to yield $\mathrm{CO}_{2}$ and other fluorinated species at temperatures of 500-600 K. TPRS and XPS results show that desorption from the $\mathrm{Cu}(100)$ surface is much slower than deprotonation so acid desorption is not detected under any experimental conditions reported in this study. Work function measurements have been used to measure the deprotonation kinetics and thus estimate the barriers to deprotonation, $\Delta E_{\mathrm{O}-\mathrm{H}}^{\ddagger}$. Correlation of acid substituent constants, $\sigma_{\mathrm{F}}$, with the $\Delta E_{\mathrm{O}-\mathrm{H}}^{\ddagger}$ shows that the transition state for acid deprotonation on $\mathrm{Cu}(100)$ is anionic with respect to the adsorbed acid $\left(\mathrm{RCO}_{2} \mathrm{H}_{(\mathrm{ad})} \leftrightarrow\left[\mathrm{RCO}_{2}{ }^{\delta-} \cdot \cdot \mathrm{H}^{\delta+}\right]^{\ddagger} \rightarrow\right)$.

\section{Experimental Section}

All experiments were performed in an UHV chamber equipped with an $\mathrm{Ar}^{+}$ion gun for cleaning the $\mathrm{Cu}(100)$ crystal surface, leak valves for gas dosing, an $\mathrm{Al} \mathrm{K} \alpha \mathrm{X}$-ray source and VG CLAM II hemispherical analyzer for X-ray photoelectron spectroscopy (XPS), and a Dycor quadrupole mass spectrometer for desorption measurements. The $\mathrm{Cu}(100)$ single-crystal sample was mounted by spot-welding between two Ta wires on a small sample holder which was then bolted to the end of the UHV sample manipulator. The manipulator allows cooling of the samples to $T<100 \mathrm{~K}$ and resistive heating to $T>1000 \mathrm{~K}$. A chromel-alumel thermocouple was spot-welded to the edge of the $\mathrm{Cu}$ sample for temperature measurement.

The $\mathrm{Cu}(100)$ sample was purchased from Monocrystals Inc. and was cleaned by several cycles of $\mathrm{Ar}^{+}$ion sputtering followed by annealing to $1000 \mathrm{~K}$. XPS was used to monitor the cleanliness of the $\mathrm{Cu}(100)$ surface.

The experiments used several fluorocarbon carboxylic acids $\left(\mathrm{CF}_{2} \mathrm{HCO}_{2} \mathrm{H}, \mathrm{CF}_{3} \mathrm{CO}_{2} \mathrm{H}, \mathrm{CF}_{2} \mathrm{HCF}_{2} \mathrm{CO}_{2} \mathrm{H}\right.$, and $\left.\mathrm{CF}_{3} \mathrm{CF}_{2} \mathrm{CO}_{2} \mathrm{H}\right)$ obtained from Aldrich Chemical Co. The acids are all liquids at room temperature and were purified by several cycles of freeze-pump -thawing. The purity of the vapor introduced into the UHV chamber through the leak valves was verified by mass spectrometry. The acids were adsorbed on the clean $\mathrm{Cu}(100)$ surfaces at $90 \mathrm{~K}$ by backfilling the chamber through a leak valve.

Temperature-programmed reaction spectroscopy (TPRS) was performed using the Dycor mass spectrometer to monitor the desorption signals at several $\mathrm{m} / \mathrm{q}$ ratios simultaneously while the sample was heated at a rate of $2 \mathrm{~K} / \mathrm{s}$. X-ray photoelectron spectroscopy (Al K $\alpha$ X-ray source and a VG CLAM II hemispherical analyzer) was performed with an X-ray source power of $600 \mathrm{~W}$ and an analyzer pass energy of $30 \mathrm{eV}$. The scan times were approximately 15 minutes for the $\mathrm{C} 1 \mathrm{~s}$ and $\mathrm{O}$ $1 \mathrm{~s}$ spectra, and 5 minutes for the $\mathrm{F} 1 \mathrm{~s}$ spectra. The binding energies of the XPS peaks were calibrated assuming that the values for the $\mathrm{Cu}$ peaks were $\mathrm{Cu} 3 \mathrm{p}_{3 / 2}=75 \mathrm{eV}, \mathrm{Cu} 3 \mathrm{p}_{1 / 2}=77$ $\mathrm{eV}, \mathrm{Cu} 3 \mathrm{~s}=123 \mathrm{eV}, \mathrm{Cu} 2 \mathrm{p}_{3 / 2}=933 \mathrm{eV}, \mathrm{Cu} 2 \mathrm{p}_{1 / 2}=953 \mathrm{eV}$, and $\mathrm{Cu} 2 \mathrm{~s}=1097 .{ }^{20}$ The surface work function was measured using a Kelvin probe (Besocke Delta PHI GmbH) with the sample positioned approximately $1 \mathrm{~mm}$ from the vibrating gold mesh electrode during heating. The work function was measured with a heating rate of $0.2 \mathrm{~K} / \mathrm{s}$ and a time constant of $t_{\mathrm{c}}=3 \mathrm{~s}$.

\section{TPRS of $\mathrm{CF}_{2} \mathrm{HCO}_{2} \mathrm{H} / \mathrm{Cu}(100)$}

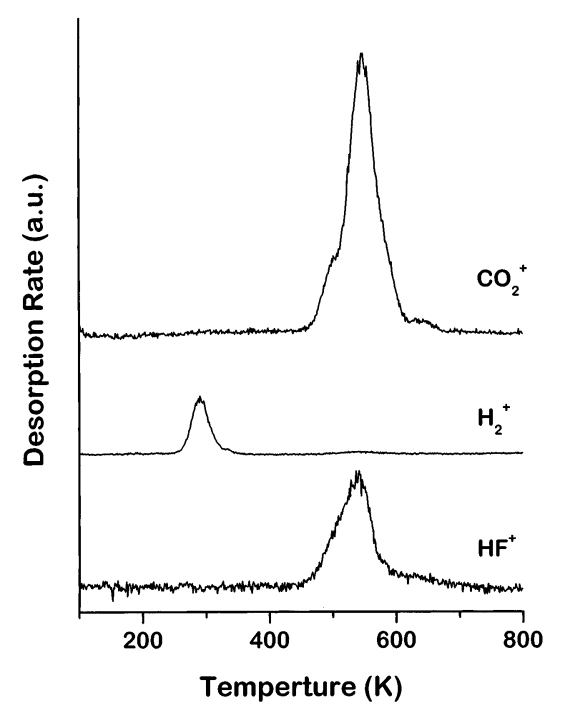

Figure 1. TPR spectrum of $\mathrm{CF}_{2} \mathrm{HCO}_{2} \mathrm{H}$ monolayer on the $\mathrm{Cu}(100)$ surface at saturation coverage. The heating rate was $\beta=2 \mathrm{~K} / \mathrm{s}$. Signals were monitored at $m / q=2,20$, and 44 .

\section{Results}

3.1. $\mathrm{CF}_{2} \mathrm{HCO}_{2} \mathrm{H}$ on $\mathrm{Cu}(\mathbf{1 0 0})$. The $\mathrm{CF}_{2} \mathrm{HCO}_{2} \mathrm{H}$ monolayer is irreversibly adsorbed on the $\mathrm{Cu}(100)$ surface and decomposes during heating. TPRS of a $\mathrm{CF}_{2} \mathrm{HCO}_{2} \mathrm{H}$ monolayer on $\mathrm{Cu}(100)$ is shown in Figure 1. The monolayer is defined as the highest coverage that can be adsorbed on the $\mathrm{Cu}(100)$ surface before some multilayer desorption is observed during TPRS measurements. $\mathrm{H}_{2}, \mathrm{HF}$, and $\mathrm{CO}_{2}$ desorption signals at $\mathrm{m} / q=2,20$, and 44 amu were monitored during heating. $\mathrm{H}_{2}$ desorption is detected at $T \sim 300 \mathrm{~K}$ while $\mathrm{CO}_{2}$ and $\mathrm{HF}$ desorption occur at $T \sim 540$ $\mathrm{K}$. The TPR spectra of $\mathrm{CF}_{2} \mathrm{HCO}_{2} \mathrm{H}$ suggest that during heating the acid deprotonates to form $\mathrm{CF}_{2} \mathrm{HCO}_{2}$ on the surface at temperatures below $300 \mathrm{~K}$. At $290 \mathrm{~K}$ the $\mathrm{H}$ atoms recombine and desorb from the surface as a $\mathrm{H}_{2}$. Desorption of $\mathrm{H}_{2}$ at this temperature is rate limited by $\mathrm{H}$ atom recombination. ${ }^{21} \mathrm{CF}_{2}$ $\mathrm{HCO}_{2}$ is stable on the surface at temperatures up to $T \sim 450 \mathrm{~K}$ at which point it begins to decompose to yield desorption of $\mathrm{CO}_{2}, \mathrm{HF}$, and other fragments.

XPS has been used to show that the $\mathrm{CF}_{2} \mathrm{HCO}_{2} \mathrm{H}$ decomposition intermediate is $\mathrm{CF}_{2} \mathrm{HCO}_{2}$. Figure 2 shows $\mathrm{C} 1 \mathrm{~s}$ and $\mathrm{O} 1 \mathrm{~s}$ $\mathrm{XP}$ spectra of the $\mathrm{CF}_{2} \mathrm{HCO}_{2} \mathrm{H}$ monolayer adsorbed on the $\mathrm{Cu}$ (100) surface at $90 \mathrm{~K}$. The $\mathrm{C} 1 \mathrm{~s}$ spectrum of the $\mathrm{CF}_{2} \mathrm{HCO}_{2} \mathrm{H}$ monolayer exhibits a major peak at a binding energy of 289.4 $\mathrm{eV}$ with a small shoulder at $288.2 \mathrm{eV}$. After annealing to 350 $\mathrm{K}$, the $\mathrm{C} 1 \mathrm{~s}$ region reveals two poorly resolved peaks at 287.2 and $288.5 \mathrm{eV}$ which have similar intensity and are assigned to the $-\mathrm{CO}_{2}$ and $-\mathrm{CF}_{2} \mathrm{H}$ groups of $\mathrm{CF}_{2} \mathrm{HCO}_{2}$, respectively. The $\mathrm{O}$ 1s XP peak in $\mathrm{CF}_{2} \mathrm{HCO}_{2} \mathrm{H}$ adsorbed at $90 \mathrm{~K}$ is observed at a binding energy of $531.8 \mathrm{eV}$ with a peak width of $\sim 2.5 \mathrm{eV}$. After annealing the $\mathrm{Cu}(100)$ surface to $350 \mathrm{~K}$, the $\mathrm{O} 1 \mathrm{~s}$ peak shifts from 531.8 to $530.6 \mathrm{eV}$ and the peak width decreases from 2.5 to $1.8 \mathrm{eV}$. The $\mathrm{C} 1 \mathrm{~s}$ and $\mathrm{O} 1 \mathrm{~s}$ peak shifts are consistent with a reaction mechanism in which $\mathrm{CF}_{2} \mathrm{HCO}_{2} \mathrm{H}$ adsorbs molecularly onto the $\mathrm{Cu}(100)$ surface at $90 \mathrm{~K}$ and then undergoes deprotonation to form $\mathrm{CF}_{2} \mathrm{HCO}_{2}$ on the surface upon annealing to $350 \mathrm{~K}$. The proposed formation of $\mathrm{CF}_{2} \mathrm{HCO}_{2}$ is supported by the decrease in the $\mathrm{O} 1 \mathrm{~s} \mathrm{XP}$ peak width upon heating the surface to $350 \mathrm{~K}$, indicating that both oxygen atoms become chemically equivalent in their bonding to the $\mathrm{Cu}(100)$ 
$\mathrm{C} 1 \mathrm{~s}$ and $\mathrm{O} 1 \mathrm{~s} X P S-\mathrm{CF}_{2} \mathrm{HCO}_{2} \mathrm{H} / \mathrm{Cu}(100)$

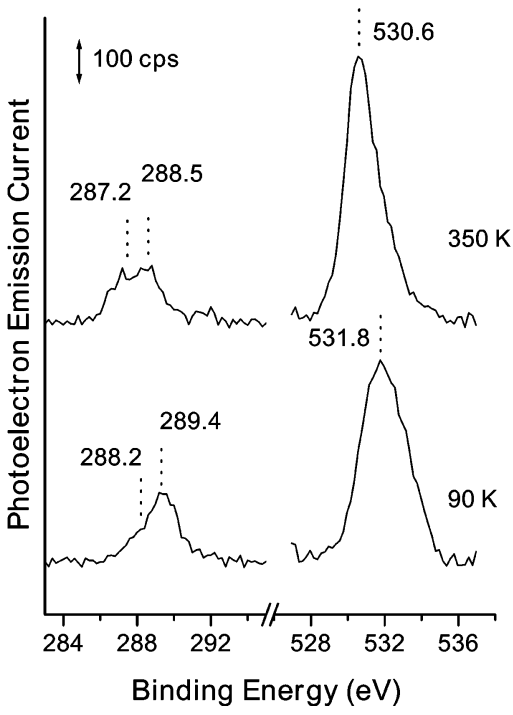

Figure 2. $\mathrm{C} 1 \mathrm{~s}$ and $\mathrm{O} 1 \mathrm{~s} \mathrm{XP}$ spectra of $\mathrm{CF}_{2} \mathrm{HCO}_{2} \mathrm{H}$ on the $\mathrm{Cu}(100)$ surface at $90 \mathrm{~K}$ and after annealing the surface to $350 \mathrm{~K}$. After heating to $350 \mathrm{~K}$, the $\mathrm{C} 1 \mathrm{~s}$ photoemission peaks from the $-\mathrm{CO}_{2}$ and $\mathrm{CF}_{2} \mathrm{H}-$ groups appear at 287.2 and $288.5 \mathrm{eV}$, respectively. The $\mathrm{O} 1 \mathrm{~s}$ spectrum for $\mathrm{CF}_{2} \mathrm{HCO}_{2} \mathrm{H}$ obtained at $90 \mathrm{~K}$ reveals a broad peak at a binding energy of $531.8 \mathrm{eV}$. After heating the surface to $350 \mathrm{~K}$ to produce the adsorbed $\mathrm{CF}_{2} \mathrm{HCO}_{2}$, the $\mathrm{O}$ 1s peak shifts to $530.6 \mathrm{eV}$ and becomes significantly narrower.

\section{TPRS of $\mathrm{CF}_{2} \mathrm{HCF}_{2} \mathrm{CO}_{2} \mathrm{H} / \mathrm{Cu}(100)$}

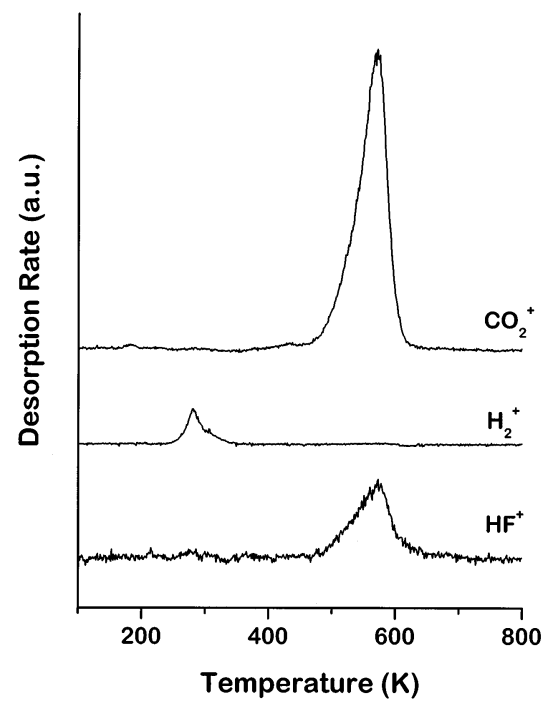

Figure 3. TPR spectrum of the $\mathrm{CF}_{2} \mathrm{HCF}_{2} \mathrm{CO}_{2} \mathrm{H}$ monolayer on the $\mathrm{Cu}(100)$ surface at saturation coverage. The heating rate was $\beta=2$ $\mathrm{K} / \mathrm{s}$. Signals were monitored at $\mathrm{m} / q=2,20$, and 44 .

surface. The decrease in the binding energy is consistent with the formation of an anionic $-\mathrm{CO}_{2}$ group.

3.2. $\mathrm{CF}_{2} \mathrm{HCF}_{2} \mathrm{CO}_{2} \mathrm{H}$ on $\mathrm{Cu}(\mathbf{1 0 0})$. As in the case of $\mathrm{CF}_{2^{-}}$ $\mathrm{HCO}_{2} \mathrm{H}$, TPR spectra (Figure 3) indicate that $\mathrm{CF}_{2} \mathrm{HCF}_{2} \mathrm{CO}_{2} \mathrm{H}$ deprotonates on the $\mathrm{Cu}(100)$ surface at temperatures below 300 $\mathrm{K}$. During heating, $\mathrm{H}_{2}$ desorption is observed at $280 \mathrm{~K}$ in the TPR spectra. $\mathrm{CF}_{2} \mathrm{HCF}_{2} \mathrm{CO}_{2}$, the deprotonation product, remains stable on the surface up to temperatures of $\sim 500 \mathrm{~K}$, at which point it begins to decompose to yield $\mathrm{HF}$ and $\mathrm{CO}_{2}$ desorption. Note that molecular desorption does not appear in the TPR spectra, indicating that all of the adsorbed acid deprotonates on the $\mathrm{Cu}(100)$ surface.

\section{$\mathrm{C} 1 \mathrm{~s}$ and $\mathrm{O}$ 1s XPS $-\mathrm{CF}_{2} \mathrm{HCF}_{2} \mathrm{CO}_{2} \mathrm{H} / \mathrm{Cu}(100)$}

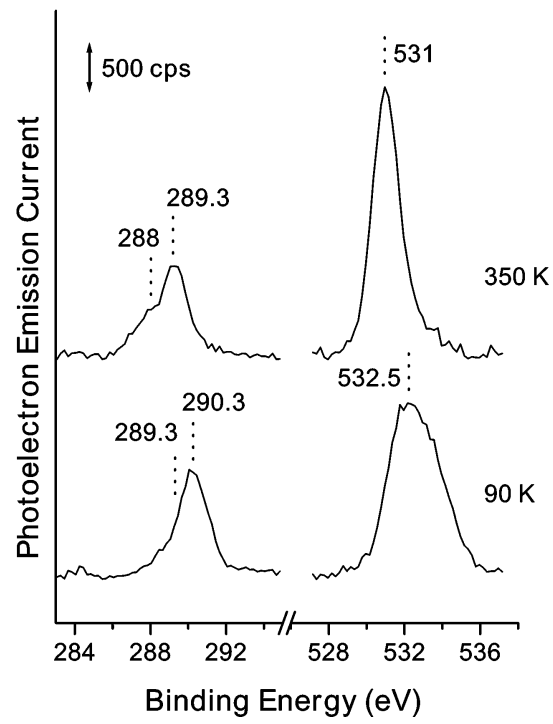

Figure 4. $\mathrm{C} 1 \mathrm{~s}$ and $\mathrm{O} 1 \mathrm{~s} \mathrm{XP}$ spectra of $\mathrm{CF}_{2} \mathrm{HCF}_{2} \mathrm{CO}_{2} \mathrm{H}$ on the $\mathrm{Cu}(100)$ surface at $90 \mathrm{~K}$ and after annealing the surface to $350 \mathrm{~K}$. After heating to $350 \mathrm{~K}$, the $\mathrm{C} 1 \mathrm{~s}$ photoemission peaks from the $-\mathrm{CO}_{2}$, and $\mathrm{CF}_{2^{-}}$ $\mathrm{HCF}_{2}-$ groups appear at 288.0 and $289.3 \mathrm{eV}$, respectively. The $\mathrm{O} 1 \mathrm{~s}$ spectrum of $\mathrm{CF}_{2} \mathrm{HCF}_{2} \mathrm{CO}_{2} \mathrm{H}$ obtained at $90 \mathrm{~K}$ reveals one broad peak at a binding energy of $532.5 \mathrm{eV}$. After heating the surface to $350 \mathrm{~K}$ to produce the adsorbed $\mathrm{CF}_{2} \mathrm{HCF}_{2} \mathrm{CO}_{2}$, the $\mathrm{O}$ 1s peak shifts to $531 \mathrm{eV}$ and becomes significantly narrower.

$\mathrm{XP}$ spectra of $\mathrm{CF}_{2} \mathrm{HCF}_{2} \mathrm{CO}_{2} \mathrm{H}$ on the $\mathrm{Cu}(100)$ surface are also consistent with a process in which the acid adsorbs molecularly at $90 \mathrm{~K}$ and then deprotonates during heating. The $\mathrm{C} 1 \mathrm{~s}$ peak shown in Figure 4 for the molecular species is centered at 290.3 $\mathrm{eV}$ and is broad as a result of the contributions from the $-\mathrm{CO}_{2} \mathrm{H}$, $-\mathrm{CF}_{2} \mathrm{H}$, and $-\mathrm{CF}_{2}-$ groups. The $\mathrm{O} 1 \mathrm{~s}$ feature is centered at $532.5 \mathrm{eV}$ and is quite broad due to the contributions from two inequivalent oxygen atoms. Upon annealing the surface to 350 $\mathrm{K}$, the $\mathrm{C} 1 \mathrm{~s}$ peaks shift to 289.3 and $288 \mathrm{eV}$ and the $\mathrm{O} 1 \mathrm{~s}$ peak shifts from 532.5 to $531 \mathrm{eV}$. The $\mathrm{C} 1 \mathrm{~s}$ peaks have a 2:1 intensity ratio consistent with assignment to the $-\mathrm{CF}_{2}-$ and $-\mathrm{CF}_{2} \mathrm{H}$ groups and to the $-\mathrm{CO}_{2}$ group. The O1s peak width also decreases as the surface is annealed from 90 to $350 \mathrm{~K}$, consistent with the formation of a $\mathrm{CF}_{2} \mathrm{HCF}_{2} \mathrm{CO}_{2}$ species with two equivalent oxygen atoms.

3.3. $\mathrm{CF}_{3} \mathrm{CO}_{2} \mathrm{H}$ and $\mathrm{CF}_{3} \mathrm{CF}_{2} \mathrm{CO}_{2} \mathrm{H}$ on $\mathrm{Cu}(100)$. TPRS and XPS studies of $\mathrm{CF}_{3} \mathrm{CO}_{2} \mathrm{H}$ and $\mathrm{CF}_{3} \mathrm{CF}_{2} \mathrm{CO}_{2} \mathrm{H}$ on the $\mathrm{Cu}(100)$ surface have yielded results that are similar to those described above for $\mathrm{CF}_{2} \mathrm{HCF}_{2} \mathrm{CO}_{2} \mathrm{H}$ and $\mathrm{CF}_{2} \mathrm{HCO}_{2} \mathrm{H}$. They reveal deprotonation of both acids to yield the corresponding carboxylates on the $\mathrm{Cu}(100)$ surface at temperatures below $300 \mathrm{~K}$. During heating, the adsorbed hydrogen atoms generated by deprotonation recombine at $\sim 300 \mathrm{~K}$ to desorb as $\mathrm{H}_{2}$. The carboxylates then remained as stable intermediates on the $\mathrm{Cu}(100)$ surface up to temperatures of $>450 \mathrm{~K}$, at which point they begin to decompose. Products of the decomposition reactions that decompose into the gas phase include $\mathrm{CO}_{2}, \mathrm{HF}, \mathrm{CF}_{3}$, and other fluorinated species. Decreases in the O 1s binding energy by $1.3-$ $1.5 \mathrm{eV}$ are observed as the surface temperature increases from 90 to $350 \mathrm{~K}$. In addition, the O 1s XP peak becomes narrower as the deprotonation of the acid to produce the carboxylate renders both oxygen atoms equivalent. In summary, TPD and XPS studies of all four acids indicate that they adsorb molecularly at $90 \mathrm{~K}$ and deprotonate on heating the $\mathrm{Cu}(100)$ surface to 300 $\mathrm{K}$. There is no molecular desorption of the acid monolayers. 


$$
\Delta \Phi \text { vs. } \mathrm{T}-\mathrm{CF}_{2} \mathrm{HCO}_{2} \mathrm{H} / \mathrm{Cu}(100)
$$

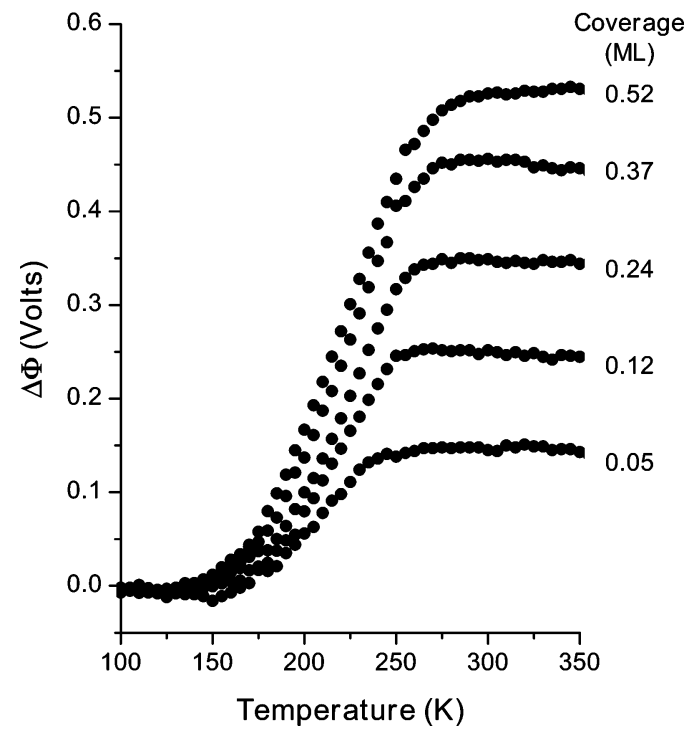

Figure 5. Work function change versus temperature during heating of $\mathrm{CF}_{2} \mathrm{HCO}_{2} \mathrm{H}$ on $\mathrm{Cu}(100)$ at various initial $\mathrm{CF}_{2} \mathrm{HCO}_{2} \mathrm{H}$ coverages. The work function change occurs as a results of the deprotonation of the $\mathrm{CF}_{2} \mathrm{HCO}_{2} \mathrm{H}$ to yield adsorbed $\mathrm{CF}_{2} \mathrm{HCO}_{2}$. The heating rate was $\beta=0.2$ $\mathrm{K} / \mathrm{s}$.

3.4. Acid Deprotonation Kinetics on $\mathbf{C u}(\mathbf{1 0 0})$. The deprotonation kinetics of the four acids on the $\mathrm{Cu}(100)$ surface have been measured using temperature-programmed work function measurements. The work function changes versus temperature for $\mathrm{CF}_{2} \mathrm{HCO}_{2} \mathrm{H}$ adsorbed on $\mathrm{Cu}(100)$ at various coverages are displayed in Figure 5. As expected, the deprotonation of the acid leads to large, easily measured changes in the surface work function. The $\mathrm{CF}_{2} \mathrm{HCO}_{2} \mathrm{H}$ coverage has been determined from the area under the $\mathrm{CO}_{2}$ TPR spectrum relative to the amount of $\mathrm{CO}_{2}$ generated by decomposition of the saturated monolayer. $\mathrm{CO}_{2}$ desorption has in turn been calibrated using XPS to show that the amount of $\mathrm{CO}_{2}$ desorption during carboxylate decomposition is in fact linear in the initial carboxylate coverage. For all initial coverages, the spectra in Figure 5 show that the work function remains fairly constant as the surface temperature increases from 90 to $150 \mathrm{~K}$. The work function changes rapidly between 150 and $250 \mathrm{~K}$, but then remains constant until the temperature reaches $350 \mathrm{~K}$. The increase of the work function during heating serves as a measure of the acid deprotonation kinetics on the $\mathrm{Cu}(100)$ surface. The magnitude of the work function change $(\Delta \Phi)$ also increases as the initial $\mathrm{CF}_{2} \mathrm{HCO}_{2} \mathrm{H}$ coverage increases. The $\Delta \Phi$ versus $T$ spectra agree with the mechanism for the surface chemistry proposed on the basis of the TPR and XP spectra. The acid adsorbs molecularly on the surface at $90 \mathrm{~K}$ and then deprotonates during heating. The positive change in the work function is consistent with the formation of an anionic carboxylate, $\mathrm{CF}_{2} \mathrm{HCO}_{2}{ }^{{ }^{-}}$, as the product and thus an increase in the surface dipole contribution to the work function. The deprotonation is complete by $250 \mathrm{~K}$, indicating that the desorption of $\mathrm{H}_{2}$ into the gas phase at $290 \mathrm{~K}$ is rate limited by $\mathrm{H}$ atom recombination on the $\mathrm{Cu}(100)$ surface..$^{21}$ Apparently, $\mathrm{H}$ atom recombination and desorption as $\mathrm{H}_{2}$ has very little influence on the work function of the surface.

Measurement of the $\mathrm{CF}_{2} \mathrm{HCO}_{2} \mathrm{H}$ deprotonation kinetics requires that we know the extent of reaction or the carboxylate coverage as a function of temperature, $\theta(T)$, during heating. To obtain the $\theta(T)$ relationship from the measured $\Delta \Phi(T)$ curves,

$$
\text { Coverage vs. } \Delta \Phi-\mathrm{CF}_{2} \mathrm{HCO}_{2} \mathrm{H} / \mathrm{Cu}(100)
$$

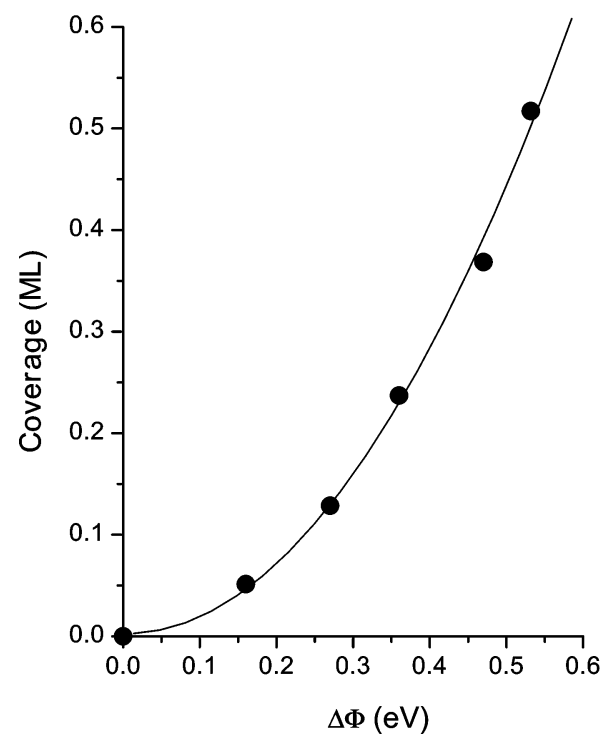

Figure 6. The $\mathrm{CF}_{2} \mathrm{HCO}_{2} \mathrm{H}$ coverage versus total work function change $(\Delta \Phi)$. The solid line is a fit of a second-order polynomial to the data.

the relationship between the initial $\mathrm{CF}_{2} \mathrm{HCO}_{2} \mathrm{H}$ coverage and the work function change, $\theta(\Delta \Phi)$, must be established. This is needed to calibrate the measurement to eliminate any effects that might lead to a nonlinear change of $\Delta \Phi$ with coverage. Figure 6 shows the plot of the initial $\mathrm{CF}_{2} \mathrm{HCO}_{2} \mathrm{H}$ coverage on the surface versus the work function change. The initial coverage of the $\mathrm{CF}_{2} \mathrm{HCO}_{2} \mathrm{H}$ was determined using the amount of $\mathrm{CO}_{2}$ desorption observed during thermal decomposition of the $\mathrm{CF}_{2}-$ $\mathrm{HCO}_{2}$ deprotonation product. The $\theta(\Delta \Phi)$ data have been fitted to a second-order polynomial function as shown in Figure 6 . The $\Delta \Phi(T)$ spectra shown in Figure 5 can then be transformed into the $\theta(T)$ curves via the fitting polynomial. The coverage of $\mathrm{CF}_{2} \mathrm{HCO}_{2}$ versus the surface temperature, $\theta(T)$, is displayed in Figure 7 for increasing initial $\mathrm{CF}_{2} \mathrm{HCO}_{2} \mathrm{H}$ coverages. The peak temperature, $T_{\mathrm{p}}$, for the deprotonation reaction is estimated from the temperatures of the inflection points of the curves in Figure 7. These inflection points can be found from the maximum in the $\mathrm{d} \theta / \mathrm{d} T$ curves shown in Figure 8 . These $\mathrm{d} \theta / \mathrm{d} T$ curves are analogous to the desorption curves observed in TPD spectra and can be used to estimate the value of $\Delta E_{\mathrm{O}-\mathrm{H}}^{\ddagger}$.

The activation barrier to acid deprotonation, $\Delta E_{\mathrm{O}-\mathrm{H}}^{\ddagger}$, can be determined from the peak reaction temperature, $T_{\mathrm{p}}$, using Redhead's equation and assuming first-order kinetics. ${ }^{22}$ First, however, one needs to determine the preexponential factor, $v$, of the deprotonation reaction. To obtain the preexponential factor, work function measurements of $\mathrm{CF}_{2} \mathrm{HCF}_{2} \mathrm{CO}_{2} \mathrm{H}$ deprotonation were performed at various heating rates in the range $\beta$ $=0.05$ to $1 \mathrm{~K} / \mathrm{s}$ and at various coverages. For each of the heating rates, the value of $T_{\mathrm{p}}$ was determined in the limit of zero coverage. In the zero coverage limit the value of $\Delta E_{\mathrm{O}-\mathrm{H}}^{\ddagger}$ for $\mathrm{CF}_{2} \mathrm{HCF}_{2} \mathrm{CO}_{2} \mathrm{H}$ deprotonation was determined from the slope of $\ln \left(\beta / T_{\mathrm{p}}{ }^{2}\right)$ versus $1 / T_{\mathrm{p}}$ shown in Figure 9. The preexponential factor, $v$, was then calculated using Redhead's equation and the value of $\Delta E_{\mathrm{O}-\mathrm{H}}^{\ddagger}$. The kinetic parameters for $\mathrm{CF}_{2} \mathrm{HCF}_{2} \mathrm{CO}_{2} \mathrm{H}$ deprotonation are $\Delta E_{\mathrm{O}-\mathrm{H}}^{\ddagger}=76.6 \pm 3.8 \mathrm{~kJ} / \mathrm{mol}$ and $v=6.2 \times$ $10^{17} \mathrm{~s}^{-1}$ in the limit of low coverage. The values of $\Delta E_{\mathrm{O}-\mathrm{H}}^{\ddagger}$ for deprotonation of all four acids at all coverages studied in this work were then calculated from Redhead's equation using a value of $v=6.2 \times 10^{17} \mathrm{~s}^{-1}$ for the preexponential factor and the experimentally determined values of $T_{\mathrm{p}}$. 


\section{$\mathrm{CF}_{2} \mathrm{HCO}_{2}$ Coverage vs. Temperature}

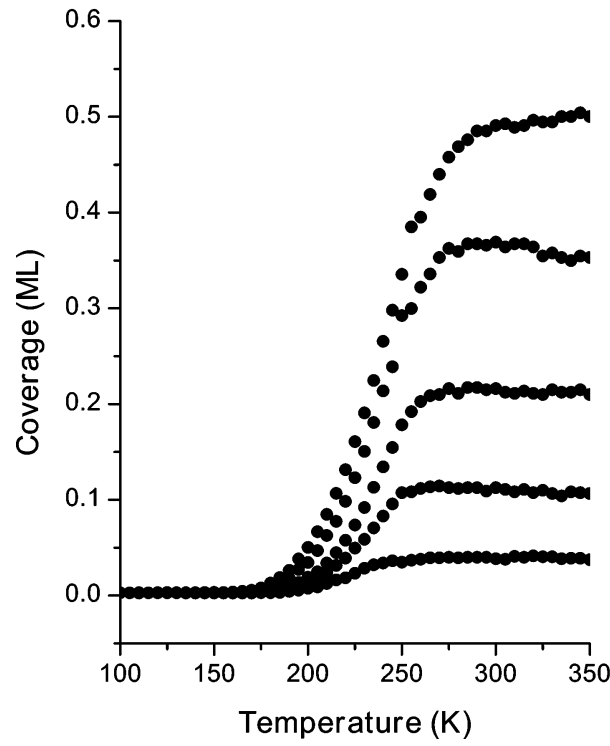

Figure 7. The $\mathrm{CF}_{2} \mathrm{HCO}_{2}$ coverage $(\theta)$ on the $\mathrm{Cu}(100)$ surface versus temperature during heating. The coverage increases as a results of the deprotonation of the adsorbed $\mathrm{CF}_{2} \mathrm{HCO}_{2} \mathrm{H}$. Curves are plotted for various different initial coverages of the $\mathrm{CF}_{2} \mathrm{HCO}_{2} \mathrm{H}$. The curves displayed were obtained by converting the work function spectra shown in Figure 5 to the $\mathrm{CF}_{2} \mathrm{HCO}_{2}$ coverage by application of the secondorder polynomial found in Figure 6.

$$
d \theta / d \mathrm{~T}-\mathrm{CF}_{2} \mathrm{HCO}_{2} \mathrm{H} / \mathrm{Cu}(100)
$$

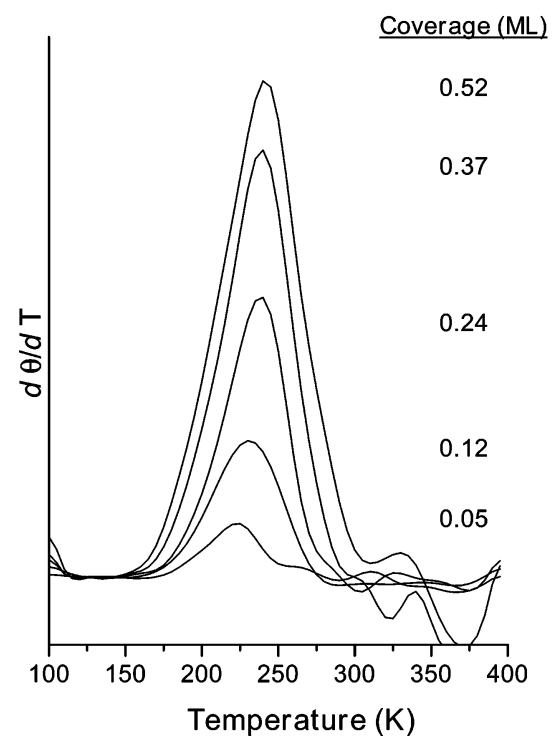

Figure 8. Derivative of the $\mathrm{CF}_{2} \mathrm{HCO}_{2}$ coverage with respect to temperature $\mathrm{d} \theta / \mathrm{d} T$ versus surface temperature at various initial $\mathrm{CF}_{2-}$ $\mathrm{HCO}_{2} \mathrm{H}$ coverages on the $\mathrm{Cu}(100)$ surface. $\mathrm{d} \theta / \mathrm{d} T$ is proportional to the rate of $\mathrm{CF}_{2} \mathrm{HCO}_{2} \mathrm{H}$ deprotonation or $\mathrm{CF}_{2} \mathrm{HCO}_{2}$ appearance. These are analogous to desorption spectra.

The work function changes during heating of $\mathrm{CF}_{3} \mathrm{CO}_{2} \mathrm{H}, \mathrm{CF}_{2}-$ $\mathrm{HCF}_{2} \mathrm{CO}_{2} \mathrm{H}, \mathrm{C}_{2} \mathrm{~F}_{5} \mathrm{CO}_{2} \mathrm{H}$ adsorbed on the $\mathrm{Cu}(100)$ surface display similar trends to that found for $\mathrm{CF}_{2} \mathrm{HCO}_{2} \mathrm{H}$. The work function is constant for temperatures below $150 \mathrm{~K}$, increases rapidly as the temperature increases from 150 to $300 \mathrm{~K}$, and then levels off once the temperature is increased past $300 \mathrm{~K}$. The $\theta(T)$ curves for all four acids at a coverage of $\theta \approx 0.1 \mathrm{ML}$ are shown together in Figure 10 for the purpose of comparison. The

\section{Deprotonation - $\mathrm{CF}_{2} \mathrm{HCF}_{2} \mathrm{CO}_{2} \mathrm{H} / \mathrm{Cu}(100)$}

$\beta=0.05-1.0 \mathrm{~K} / \mathrm{s}$

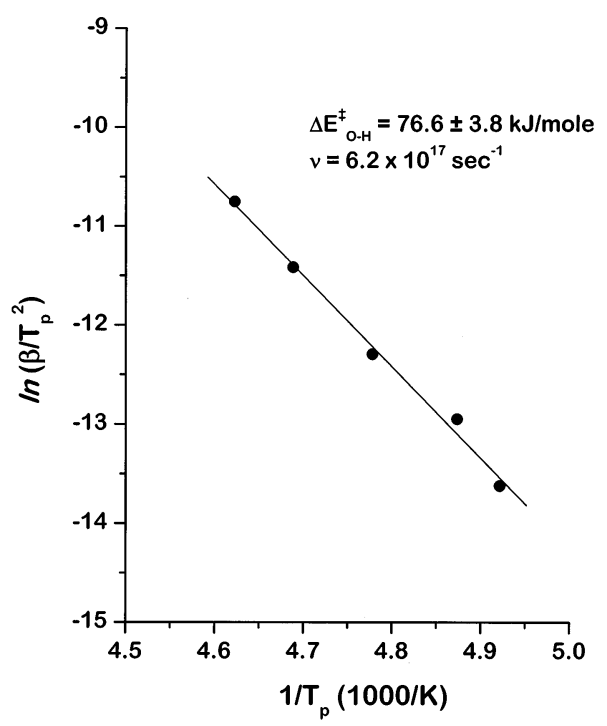

Figure 9. Plot of $\ln \left(\beta / T_{\mathrm{p}}^{2}\right)$ versus $1 / T_{\mathrm{p}}$ for $\mathrm{CF}_{3} \mathrm{CF}_{2} \mathrm{HCO}_{2} \mathrm{H}$ deprotonation on the $\mathrm{Cu}(100)$ surface measured heating rates varying from $\beta$ $=0.05$ to $1 \mathrm{~K} / \mathrm{s}$. The slope yields a value of $\Delta E_{\mathrm{O}-\mathrm{H}}^{\ddagger}=76.6 \mathrm{~kJ} / \mathrm{mol}$.

\section{$\zeta$ vs. T - Acid Deprotonation / Cu(100)}

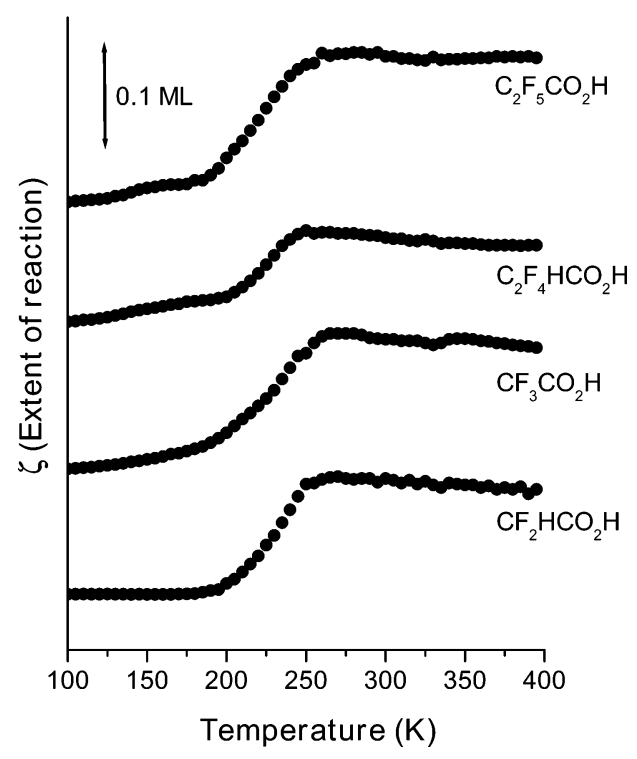

Figure 10. The extent of deprotonation $(\xi)$ measured as the carboxylate coverage versus surface temperature for $\mathrm{CF}_{2} \mathrm{HCO}_{2} \mathrm{H}, \mathrm{CF}_{3} \mathrm{CO}_{2} \mathrm{H}, \mathrm{C}_{2} \mathrm{~F}_{2}-$ $\mathrm{HCF}_{2} \mathrm{CO}_{2} \mathrm{H}$, and $\mathrm{CF}_{3} \mathrm{CF}_{2} \mathrm{CO}_{2} \mathrm{H}$ deprotonation on the $\mathrm{Cu}(100)$ surface at coverages of roughly $0.1 \mathrm{ML}$.

derivatives of the $\theta(T)$ curves give $T_{\mathrm{p}}$ for each of the acids. The values of $\Delta E_{\mathrm{O}-\mathrm{H}}^{\ddagger}$ were then calculated at various coverages using Redhead's equation and the value of $v=6.2 \times 10^{17}$ $\mathrm{s}^{-1}$ obtained for $\mathrm{CF}_{2} \mathrm{HCF}_{2} \mathrm{CO}_{2} \mathrm{H}$. The values of $\Delta E_{\mathrm{O}-\mathrm{H}}^{\ddagger}$ versus initial acid coverage are shown in Figure 11 for all fours acids. In all cases, the $\Delta E_{\mathrm{O}-\mathrm{H}}^{\ddagger}$ increases with increasing coverage but then plateaus as the coverage increases past $0.25 \mathrm{ML}$. More importantly from the perspective of this work there is a consistent decrease in the $\Delta E_{\mathrm{O}-\mathrm{H}}^{\ddagger}$ as the degree of fluorination of the acid is increased. 


\section{$\Delta \mathrm{E}_{\text {O-H }}^{\ddagger}$ vs. Coverage - Acids / Cu(100)}

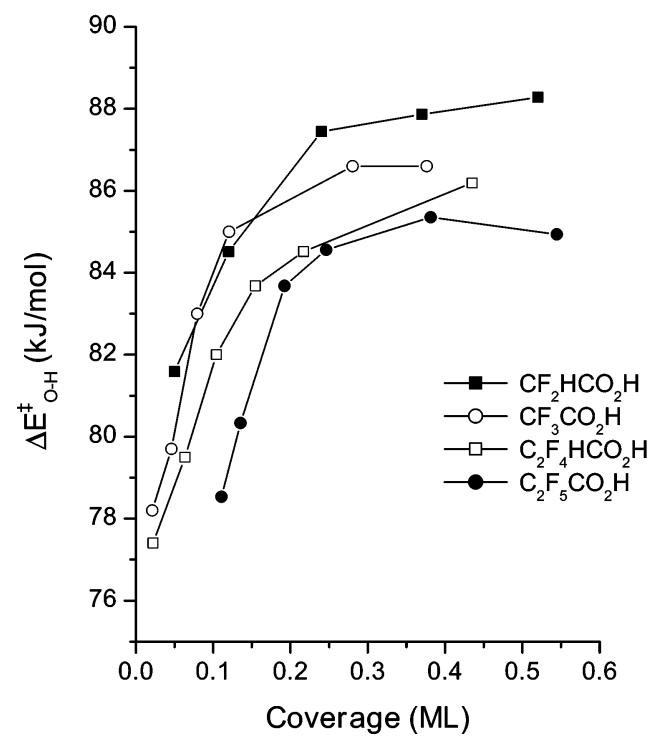

Figure 11. $\Delta E_{\mathrm{O}-\mathrm{H}}^{\stackrel{亠}{\ddagger}}$ versus initial acid coverage for $\mathrm{CF}_{2} \mathrm{HCO}_{2} \mathrm{H}, \mathrm{CF}_{3}$ $\mathrm{CO}_{2} \mathrm{H}, \mathrm{C}_{2} \mathrm{~F}_{2} \mathrm{HCF}_{2} \mathrm{CO}_{2} \mathrm{H}$, and $\mathrm{CF}_{3} \mathrm{CF}_{2} \mathrm{CO}_{2} \mathrm{H}$ on the $\mathrm{Cu}(100)$ surface.

\section{Discussion}

4.1. Transition State for Acid Deprotonation on $\mathrm{Cu}$ (100). The goal of this work is to correlate the barriers to deprotonation, $\Delta E_{\mathrm{O}-\mathrm{H}}^{\ddagger}$, with the substituent constants, $\sigma_{\mathrm{F}}$, for each of the acids in order to probe the nature of the transition state for acid deprotonation on the $\mathrm{Cu}(100)$ surface. To do this, however, we must first examine the dependence of $\Delta E_{\mathrm{O}-\mathrm{H}}^{\ddagger}$ on the acid coverage. Figure 11 shows the values of $\Delta E_{\mathrm{O}-\mathrm{H}}^{\ddagger}$ as a function of the acid coverage. At low coverages, the values of $\Delta E_{\mathrm{O}-\mathrm{H}}^{\sharp}$ increase with coverage but then reach a constant value for each acid as the coverage is increased to $\theta>0.25$ monolayers. Such a coverage-dependent $\Delta E_{\mathrm{O}-\mathrm{H}}^{\ddagger}$ has been observed by Lee et al. in a study of the deprotonation of acetic acid on the $\mathrm{Cu}(110)$ surface. ${ }^{11}$ In that work, $\Delta E_{\mathrm{O}-\mathrm{H}}^{\ddagger}$ varied from $37.6 \mathrm{~kJ} / \mathrm{mol}$ at low coverage to $106 \mathrm{~kJ} / \mathrm{mol}$ at high coverage. The origin of the coverage dependence of $\Delta E_{\mathrm{O}-\mathrm{H}}^{\ddagger}$ is not clear but may arise from hydrogen bonding between adsorbed acid molecules. In the gas phase, acetic acid molecules form hydrogen-bonded dimers at high pressure. On the Pt(111) surface, Gao et al. found that acetic acid adsorbed at intermediate coverages will also form intermolecular hydrogen bonds. ${ }^{18}$ The heat of acetic acid dimerization on the $\operatorname{Pt}(111)$ surface was reported to be $\sim 30.5$ $\mathrm{kJ} / \mathrm{mol}$. Hydrogen bonding can increase the $\Delta E_{\mathrm{O}-\mathrm{H}}^{\sharp}$ by stabilizing the acid in its protonated form on the surface. The coverage dependence of $\Delta E_{\mathrm{O}-\mathrm{H}}^{\sharp}$ that we have observed on the $\mathrm{Cu}(100)$ surface is not as great as on the $\mathrm{Cu}(110)$ surfaces. The high coverage value of $\Delta E_{\mathrm{O}-\mathrm{H}}^{\ddagger} \approx 85-90 \mathrm{~kJ} / \mathrm{mol}$ for the fluorinated acids on the $\mathrm{Cu}(100)$ surface, however, is similar to the value of $\Delta E_{\mathrm{O}-\mathrm{H}}^{\ddagger}=106 \mathrm{~kJ} / \mathrm{mol}$ observed on the $\mathrm{Cu}(110)$ surface. Furthermore, as will be shown below, one expects the value of $\Delta E_{\mathrm{O}-\mathrm{H}}^{*}$ to be lower for the fluorinated acids than for acetic acid.

Having determined the values of $\Delta E_{\mathrm{O}-\mathrm{H}}^{\ddagger}$ for all four acids at various coverages, correlations between the $\Delta E_{\mathrm{O}-\mathrm{H}}^{\ddagger}$ and the field substituent parameter, $\sigma_{\mathrm{F}}$, can be examined. Since the activation energies are coverage dependent, we have made the correlations using the values in the limit of zero coverage, $\left(\Delta E_{\mathrm{O}-\mathrm{H}}^{\ddagger}\right)_{0}$, and at a coverage of $1 / 2 \mathrm{ML},\left(\Delta E_{\mathrm{O}-\mathrm{H}}^{\ddagger}\right)_{1 / 2}$. The
TABLE 1: The Field Substituent Constants of the Fluoroalkyl Groups of Carboxylic Acids

\begin{tabular}{lc}
\hline substituent & field constant $\left(\sigma_{\mathrm{F}}\right)$ \\
\hline $\mathrm{CF}_{2} \mathrm{H}-$ & $0.29^{a}$ \\
$\mathrm{CF}_{3}-$ & $0.38^{a}$ \\
$\mathrm{CF}_{2} \mathrm{HCF}_{2}-$ & $0.41^{b}$ \\
$\mathrm{CF}_{3} \mathrm{CF}_{2}-$ & $0.44^{a}$
\end{tabular}

${ }^{a}$ Table 1 of ref $24{ }^{b}$ Interpolation of $\sigma_{\mathrm{F}}$ for $\mathrm{CF}_{2} \mathrm{H}$ and $\mathrm{CF}_{3} \mathrm{CF}_{2}$.

\section{LFER - Acid Deprotonation on Cu(100)}

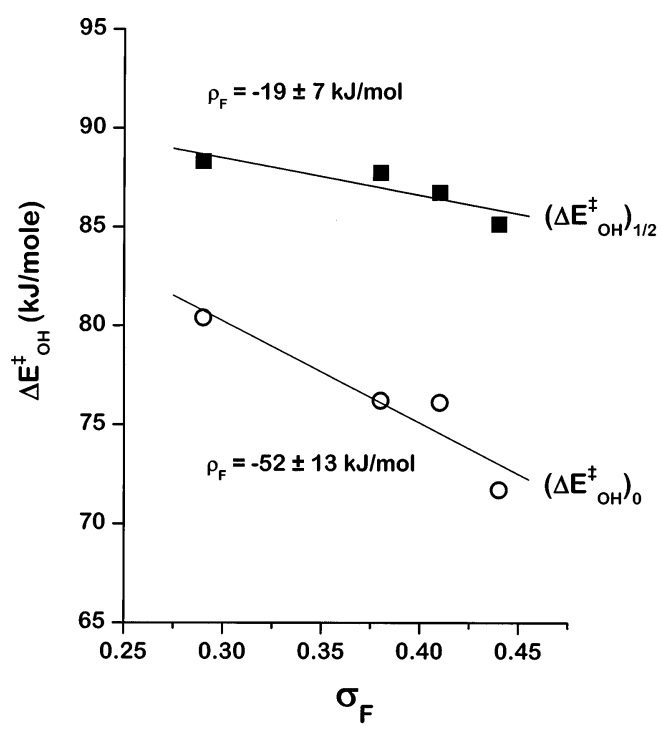

Figure 12. Linear free energy relationship for the carboxylic acid deprotonation reaction on the $\mathrm{Cu}(100)$ surface. The reaction constants are $\rho_{\mathrm{F}}=-52 \pm 13 \mathrm{~kJ} / \mathrm{mol}$ in the limit of zero coverage and $\rho_{\mathrm{F}}=-19$ $\pm 7 \mathrm{~kJ} / \mathrm{mol}$ at $1 / 2 \mathrm{ML}$ coverage.

activation energies at zero and half coverages were determined from Figure 11. The values of $\left(\Delta E_{\mathrm{O}-\mathrm{H}}^{\vdots}\right)_{0}$ were estimated by extrapolating the region of the curve in which the $\Delta E_{\mathrm{O}-\mathrm{H}}^{\ddagger}$ still increases with coverage to the intercept with $y$-axis. The values of $\left(\Delta E_{\mathrm{O}-\mathrm{H}}^{\ddagger}\right)_{1 / 2}$ were determined from the values of $\Delta E_{\mathrm{O}-\mathrm{H}}^{\ddagger}$ at coverages greater than 0.25 monolayers at which point they are coverage independent. The correlations between the $\Delta E_{\mathrm{O}-\mathrm{H}}^{\ddagger}$ and the $\sigma_{\mathrm{F}}$ take the form of linear free energy relationships. ${ }^{23,24}$ The field substituent constants are empirical measures of the dipole moment of the substituent group. As shown in Table 1, increasing the fluorine content of the alkyl groups results in larger substituent constants. Note that the value of $\sigma_{\mathrm{F}}$ for the $\mathrm{CF}_{2} \mathrm{HCF}_{2}-$ group has not been reported in the literature and has been estimated in this work by interpolating between the values for the $\mathrm{CF}_{3}\left(\sigma_{\mathrm{F}}=0.38\right)$ and $\mathrm{C}_{2} \mathrm{~F}_{5}\left(\sigma_{\mathrm{F}}=0.44\right)$ groups. ${ }^{24}$ The correlations between the values of $\Delta E_{\mathrm{O}-\mathrm{H}}^{\ddagger}$ and $\sigma_{\mathrm{F}}$ yield straight lines as shown in Figure 12.

The nature of the transition state for acid deprotonation on the $\mathrm{Cu}(100)$ surface can be inferred from the slope of the LFER, $\rho_{\mathrm{F}}$, also known as the reaction constant. For an elementary reaction with a transition state which is cationic with respect to the reactant, substituents with higher values of $\sigma_{\mathrm{F}}$ raise the activation barrier by destabilizing the cationic transition state with respect to the reactant. As an example, the $\beta$-hydride elimination reaction of alkoxides to aldehydes on the $\mathrm{Cu}(111)$ surface yields $\rho_{\mathrm{F}}=150 \mathrm{~kJ} / \mathrm{mol}^{2,3}$ Therefore, the transition state for $\beta$-hydride elimination is cationic, $\left[\mathrm{R}-\mathrm{C}^{\delta+} \cdot \mathrm{H}^{\delta-}\right]^{\ddagger}$. If $\rho_{\mathrm{F}} \approx$ 0 , then the electron density distribution in the transition state is not much different from that in the adsorbed reactant. This is 
the case for dehalogenation reactions on the $\mathrm{Ag}(111)$ and $\mathrm{Pd}-$ (111) surfaces. ${ }^{4-6}$ Finally, a negative value of $\rho_{\mathrm{F}}$ indicates that fluorination of the substituents stabilizes the transition state with respect to the adsorbed reactant. This implies that the transition state is anionic, as one would expect for the deprotonation of acids in the gas phase.

The LFER for deprotonation of the carboxylic acids shows that fluorination of the substituents on the acids lowers the value of the $\Delta E_{\mathrm{O}-\mathrm{H}}^{\dot{\dagger}}$, as illustrated in Figure 12. The values of $\rho_{\mathrm{F}}$ determined in the limit of low coverage and for a coverage of $1 / 2 \mathrm{ML}$ are found to be $\left(\Delta E_{\mathrm{O}-\mathrm{H}}^{*}\right)_{0}=-52 \pm 13 \mathrm{~kJ} / \mathrm{mol}$ and $\left(\Delta E_{\mathrm{O}-\mathrm{H}}^{\ddagger}\right)_{1 / 2}=-19 \pm 7 \mathrm{~kJ} / \mathrm{mol}$, respectively. To put these values into perspective they can be compared with the values of the reaction constants for acid deprotonation and dehydrogenation in the gas phase. In the gas phase, the heat of deprotonation of $\mathrm{CF}_{3} \mathrm{CO}_{2} \mathrm{H}$ is $105 \mathrm{~kJ} / \mathrm{mol}$ lower than that of $\mathrm{CH}_{3} \mathrm{CO}_{2} \mathrm{H}$. The $\mathrm{CF}_{3}$ group stabilizes the anionic acetate product, $\mathrm{RCO}_{2}{ }^{-}{ }^{25-27}$ The value of the reaction constant for carboxylic acid deprotonation in the gas phase can be estimated at $\rho_{\mathrm{F}}=$ $-104 \mathrm{~kJ} / \mathrm{mol}$ from the gas-phase acidities of acetic acid and its fluorinated derivatives. ${ }^{23}$ In comparison, the reaction constant for simple, homolytic $\mathrm{O}-\mathrm{H}$ bond cleavage of the carboxylic acids in the gas phase is $\rho_{\mathrm{F}}=0 \mathrm{~kJ} / \mathrm{mol}$. In other words, fluorination of the methyl group in acetic acid does not have any influence on the relative energies of the gas-phase acids and their corresponding carboxyl radicals, $\mathrm{R}-\mathrm{CO}_{2} \bullet$. The range of values that we have found for the reaction constants for acid deprotonation on the $\mathrm{Cu}(100)$ are significant in magnitude to those for gas-phase acid deprotonation. This suggests that the transition state for acid deprotonation on the $\mathrm{Cu}(100)$ surface is anionic with respect to the reactant.

$$
\mathrm{RCO}_{2} \mathrm{H}_{(\mathrm{ad})} \leftrightarrow\left[\mathrm{RCO}_{2}{ }^{\delta-} \cdot \cdots \mathrm{H}^{\delta+}\right]^{\ddagger}
$$

The reaction constant for acid deprotonation on the $\mathrm{Cu}(100)$ surface, $\rho_{\mathrm{F}}=-19$ to $-52 \mathrm{~kJ} / \mathrm{mol}$, is lower than that for deprotonation in the gas phase, $\rho_{\mathrm{F}}=-104 \mathrm{~kJ} / \mathrm{mol}$. One obvious explanation is that the charge separation in the transition state on the $\mathrm{Cu}(100)$ surface is not as large as that of the acetate anion and proton produced by gas-phase deprotonation. This is not surprising since the metal is likely to delocalize some of the charge on the carboxylate anion product adsorbed on the surface. Alternately, the presence of the metal may serve to screen the charged transition state in much the same way as water screens and stabilizes the carboxylate anions produced by acid deprotonation in the aqueous phase. The charge separation in the transition state is, however, consistent with the view based on the work function and XPS results that the product carboxylate on the $\mathrm{Cu}(100)$ surface should be considered anionic.

All four fluorinated acids studied in this work deprotonate spontaneously on the $\mathrm{Cu}(100)$ surface at temperatures in the range $150-300 \mathrm{~K}$. The values of $\Delta E_{\mathrm{O}-\mathrm{H}}^{\dagger}$ measured at high coverages of the fluorinated acids on $\mathrm{Cu}(100)$ fall in the range $\Delta E_{\mathrm{O}-\mathrm{H}}^{\ddagger}=85-90 \mathrm{~kJ} / \mathrm{mol}$ and are similar to the value of $\Delta E_{\mathrm{O}-\mathrm{H}}^{*}=106 \mathrm{~kJ} / \mathrm{mol}$ reported by Lee et al. for acetic acid on $\mathrm{Cu}(110) .{ }^{11}$ Our linear free energy relationship depicted in Figure 12 predicts a value of $\Delta E_{\mathrm{O}-\mathrm{H}}^{\ddagger}=94 \mathrm{~kJ} / \mathrm{mol}$ for acetic acid on the $\mathrm{Cu}(100)$ surface at high coverage. The principal difference between the results on the $\mathrm{Cu}(100)$ and $\mathrm{Cu}(110)$ surfaces is that the low coverage values of $\Delta E_{\mathrm{O}-\mathrm{H}}^{\ddagger}$ differ substantially. On the $\mathrm{Cu}(110)$ surface the value of $\Delta E_{\mathrm{O}-\mathrm{H}}^{\ddagger}$ for acetic acid is very coverage dependent and drops from $\Delta E_{\mathrm{O}-\mathrm{H}}^{\ddagger}=106 \mathrm{~kJ} / \mathrm{mol}$ to $\Delta E_{\mathrm{O}-\mathrm{H}}^{\sharp}=37.6 \mathrm{~kJ} / \mathrm{mol}$ at low coverage. The coverage depen- dence is attributed to stabilization of the initial state acid by hydrogen bonding as one increases the coverage. The difference between the $\mathrm{Cu}(100)$ and $\mathrm{Cu}(110)$ surface might be that the corrugated nature of the $\mathrm{Cu}(110)$ surface inhibits hydrogen bonding between adsorbed acids at low coverages, whereas this occurs quite readily at low coverages on the $\mathrm{Cu}(100)$ surface. The similarities between the results at high coverages on the two surfaces are satisfying; however, the differences at low coverages have yet to be resolved.

4.2. Thermochemistry of Acid Deprotonation on $\mathrm{Cu}(100)$. The fact that both the transition state and the carboxylate product of acid deprotonation on the $\mathrm{Cu}(100)$ surface are anionic with respect to the adsorbed acid does not imply that the transition state must be product-like. Hammond's postulate suggests that for an exothermic reaction the transition state occurs early in the reaction coordinate. ${ }^{28}$ Although there is not enough data to determine the reaction energetics for deprotonation of the fluorinated acids used in this work on the $\mathrm{Cu}(100)$ surface, a Born-Haber cycle for deprotonation of acetic acid on the $\mathrm{Cu}(110)$ surface can be constructed. This is shown below and indicates that the acid deprotonation reaction is exothermic. The

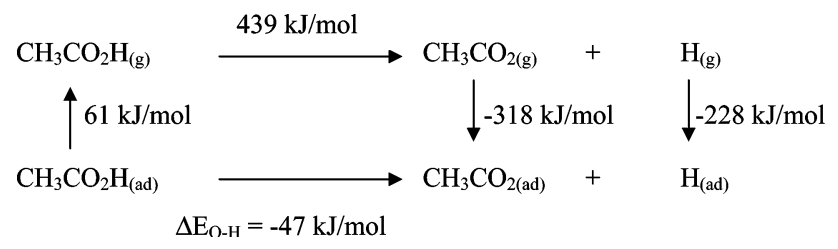

desorption energy of the acid is determined from Redhead's equation using the desorption temperature of $240 \mathrm{~K}$ reported by Bowker et al. ${ }^{16}$ and a preexponential factor of $10^{13} \mathrm{~s}^{-1}$. The heat of the homolytic acetic acid dehydrogenation reaction to acetyl and a hydrogen atom in the gas phase has been determined experimentally. ${ }^{26,27}$ The adsorption energies of $\Delta E_{\text {ads }}$ $=-318 \mathrm{~kJ} / \mathrm{mol}$ for acetyl and $\Delta E_{\mathrm{ads}}=-228 \mathrm{~kJ} / \mathrm{mol}$ for a hydrogen atom on $\mathrm{Cu}(110)$ have been obtained from electronic structure calculations. ${ }^{29,30}$ Other, experimentally and computationally determined values for these quantities suggest that they are even greater in magnitude and would make the energetics of the surface deprotonation reaction even more exothermic. ${ }^{21,29}$ The Born-Haber cycle predicts the net reaction energy for acetic acid deprotonation on the $\mathrm{Cu}(110)$ surface to be $\Delta E_{\mathrm{O}-\mathrm{H}}$ $=-47 \mathrm{~kJ} / \mathrm{mol}$. In other words, the reaction is exothermic and according to Hammond's postulate would be reactant-like, occurring early in the reaction coordinate. To relate this analysis of the deprotonation energetics of acetic acid on the $\mathrm{Cu}(110)$ surface to those of the fluorinated acids on the $\mathrm{Cu}(100)$ surface we must consider the effects of fluorination on each of the relevant elementary steps of the Born-Haber cycle. Fluorination of ethanol has been shown to lower the desorption energy from the $\mathrm{Ag}(110)$ and $\mathrm{Cu}(111)$ surfaces slightly but not sufficiently to change the sign of the net energetics for the surface deprotonation reaction. ${ }^{2,31}$ Similarly, fluorination of acetic acid has been shown to have very little influence on the energetics of homolytic $\mathrm{O}-\mathrm{H}$ bond cleavage in the gas phase. ${ }^{26,27}$ On the other hand, if the product carboxylates are anionic on the $\mathrm{Cu}$ surfaces, then fluorination ought to stabilize the product significantly with respect to the reactant and render deprotonation of the fluorinated acids even more exothermic than for acetic acid. This is analogous to the fact that fluorination of the acetic acids reduces the gas-phase heat of deprotonation substantially. ${ }^{25-27}$ Thus all indications are that carboxylic acid deprotonation on the $\mathrm{Cu}(100)$ surface is exothermic and suggests, in accordance with Hammond's postulate and our 


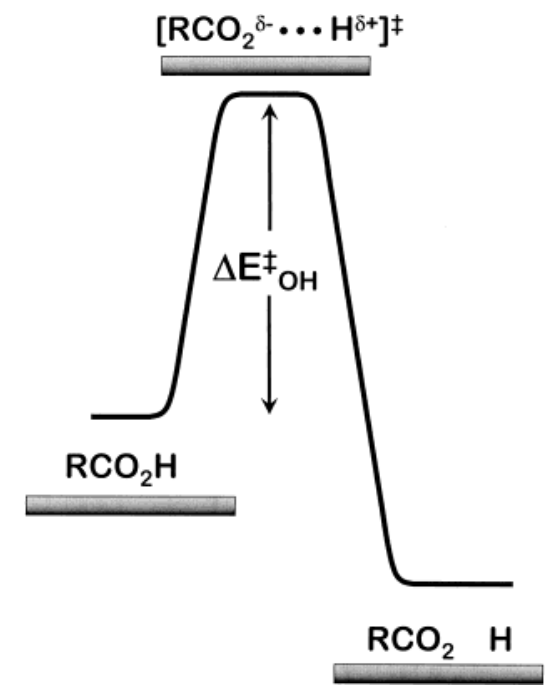

Figure 13. Potential energy diagram for acid deprotonation on the $\mathrm{Cu}(100)$ surface. The transition state is anionic with respect to the acid, and the reaction is exothermic.

experimental results, that the transition state is anionic and occurs early in the reaction coordinate. Figure 13 depicts a potential energy diagram for acid deprotonation that is consistent with our understanding based on the work presented in this paper.

\section{Conclusion}

$\mathrm{CF}_{2} \mathrm{HCO}_{2} \mathrm{H}, \mathrm{CF}_{3} \mathrm{CO}_{2} \mathrm{H}, \mathrm{CF}_{2} \mathrm{HCF}_{2} \mathrm{CO}_{2} \mathrm{H}$, and $\mathrm{CF}_{3} \mathrm{CF}_{2} \mathrm{CO}_{2} \mathrm{H}$ all deprotonate on the $\mathrm{Cu}(100)$ surface at surface temperatures below $300 \mathrm{~K}$. The field reaction constants for the acid deprotonation reaction derived from LFERs are $\rho_{\mathrm{F}}=-52 \pm 13 \mathrm{~kJ} /$ mol in the limit of zero coverage and $\rho_{\mathrm{F}}=-19 \pm 7 \mathrm{~kJ} / \mathrm{mol}$ at $1 / 2 \mathrm{ML}$ coverage. This indicates that the transition state for acid deprotonation on the $\mathrm{Cu}(100)$ surface is anionic with respect to the reactant.

Acknowledgment. This work has been funded by Grant CHE-0091765 from the National Science Foundation.

\section{References and Notes}

(1) Gellman, A. J. Acc. Chem. Res. 2000, 33, 19-26.

(2) Dai, Q.; Gellman, A. J. J. Phys. Chem. 1993, 97, 10783-10789.

(3) Gellman, A. J.; Dai, Q. J. Am. Chem. Soc. 1993, 115, 714-722.

(4) Buelow, M. T.; Zhou, G.; Gellman, A. J.; Immaraporn, B. Catal. Lett. 1999, 59, 9-13.

(5) Buelow, M. T.; Immaraporn, B.; Gellman, A. J. J. Catal. 2001, $203,41-50$ 1448

(6) Buelow, M. T.; Gellman, A. J. J. Am. Chem. Soc. 2001, 123, 1440-

(7) Gulkova, D.; Kraus, M. J. Mol. Catal. 1994, 87, 47-55.

(8) Gulkova, D.; Kraus, M. Collect. Czech. Chem. Commun. 1992, 57 , $2215-2226$.

(9) Kraus, M. Adv. Catal. 1980, 29, 151-196.

(10) Parker, B.; Immaraporn, B.; Gellman, A. J. Langmuir 2001, 17, $6638-6646$

(11) Lee, J. G.; Ahner, J.; Mocuta, D.; Denev, S.; Yates, J. T. J. Chem. Phys. 2000, 112, 3351-3357.

(12) Caputi, L. S.; Chiarello, G.; Lancellotti, M. G.; Rizzi, G. A.; Sambi, M.; Granozzi, G. Surf. Sci. 1993, 291, L756-L758.

(13) Bowker, M.; Rowbotham, E.; Leibsle, F. M.; Haq, S. Surf. Sci. 1996, 349, 97-110

(14) Crapper, M. D.; Riley, C. E.; Woodruff, D. P. Surf. Sci. 1987, 184 , 121-136.

(15) Hayden, B. E.; Prince, K.; Woodruff, D. P.; Bradshaw, A. M. Surf. Sci. 1983, 133, 589-604.

(16) Bowker, M.; Madix, R. J. Appl. Surf. Sci. 1981, 8, 299-317.

(17) Ying, D. H. S.; Madix, R. J. J. Catal. 1980, 61, 48-56.

(18) Gao, Q. Y.; Hemminger, J. C. Surf. Sci. 1991, 248, 45-56.

(19) Avery, N. R. J. Vac. Sci. Technol. 1982, 20, 592-593.

(20) Wagner, C. D.; Riggs, W. M.; Davis, L. E.; Moulder, J. F.;

Muilenberg, G. E. Handbook of X-ray Photoelectron Spectroscopy; PerkinElmer Corp.: Eden Prairie, MN, 1979.

(21) Kolovos-Vellianitis, D.; Kammler, T.; Kuppers, J. Surf. Sci. 2000 $454,316-319$.

(22) Redhead, P. A. Vacuum 1962, 12, 203-211.

(23) Taft, R. W. Prog. Phys. Org. Chem. 1983, 14, 247-350.

(24) Hansch, C.; Leo, A.; Taft, R. W. Chem. Rev. 1991, 91, 165-195.

(25) Caldwell, G.; Renneboog, R.; Kebarle, P. Can. J. Chem.-Rev. Can Chim. 1989, 67, 611-618.

(26) Lias, S. G.; Bartmess, J. E.; Liebman, J. F.; Holmes, J. L.; Levin, R. D.; Mallard, W. G. J. Phys. Chem. Ref. Data 1988, 17, 1.

(27) Cumming, J. B.; Kebarle, P. Can. J. Chem.-Rev. Can. Chim. 1978, $56,1-9$.

(28) Hammond, G. S. J. Am. Chem. Soc. 1955, 77, 334-338.

(29) Karis, O.; Hasselstrom, J.; Wassdahl, N.; Weinelt, M.; Nilsson, A.; Nyberg, M.; Pettersson, L. G. M.; Stohr, J.; Samant, M. G. J. Chem. Phys. 2000, 112, 8146-8155.

(30) Bae, C. S.; Freeman, D. L.; Doll, J. D.; Kresse, G.; Hafner, J. J. Chem. Phys. 2000, 113, 6926-6932.

(31) Dai, Q.; Gellman, A. J. J. Phys. Chem. 1991, 95, 9443-9448. 